\title{
Analysis and Design of Filament Power Supply with Voltage-Fed Single-Switch ZVS Inverter
}

\author{
Yueh-Ru Yang \\ Ming Chi University of Technology, New Taipei City, Taiwan
}

\begin{abstract}
In this paper, an off-line voltage-fed single-switch zero-voltage-switching (ZVS) inverter is analyzed and designed for the filament power supply of cooker magnetrons. Due to the low resistance of cathode filament, an isolation transformer with large turn ratio is used. To obtain the ZVS operation, a parallel-resonant capacitor is connected to the primary of transformer. The capacitor, transformer and filament constitute a parallel resonant tank. Both the transformer leakage inductance and the transistor output capacitance are merged into the resonant tank. The resonant energy provides the ZVS operation of the inverter switch, and the secondary voltage drives the cathode filament. To verify the analysis, a prototype inverter is built and tested. Experimental results validate the circuit design.
\end{abstract}

\section{Introduction}

Microwave heating is an important contactless heating approach and the related techniques and applications in household, industrial, agricultural and medical fields are continuously developed [1-3]. The microwave generator of microwave ovens is a continuous-wave magnetron. Its basic components include a hollow metal cylinder, a cathode filament, two ring magnets, even-number anode resonant cavities and an output antenna. The cathode filament is located in the central of the hollow cylinder and is surrounded by the even-number anode cavities. The space between the anode and cathode is the working space of magnetron. In the space, the dc voltage between anode and cathode forms a horizontal electric field and the two ring magnets respectively located on the top and bottom of the hollow cylinder build a vertical magnetic field. As the cathode filament is heated to a critical temperature, the cathode filament emits thermal electrons to the working space. Then, the perpendicular electric and magnetic fields respectively exert forces to the space electrons. As the space electrons sweep across the opening of anode cavities, the polarities of adjacent anode vanes are alternately changed and hence the LC resonance of the anode cavities is caused. At proper conditions, the space electron clouds eventually form rotating spokes. As the spoke number is a half of the anode cavity number, the magnetron enters the pi mode operation. To easily enter the pi mode, the even and the odd anode vanes are respectively tied together. The anode output antenna intercepts the energy of anode resonant cavities and radiates microwaves. With the constant magnetic and electric fields, the anode power is determined by the average anode current.

The cathode filament is the heart of magnetrons. To prolong the usable life, the filament should be preheated to the thermionic emission temperature before applying negative high voltage to the cathode filament. In general, the pre-heating of cathode filament may take more than two seconds. Inappropriate start-up and filament temperature usually shorten the filament life and degrade the performance. In order to keep filament at proper temperature, the filament driving voltage should be decreased with the average anode current. Shown in Fig. 1 is an example that the filament driving voltage decreases with the average anode current. Accordingly, as shown in Fig.2, besides the anode power supply (APS), a complete magnetron driver needs a separate filament power supply (FPS) to preheat and regulate the filament power. In this work, the voltage source $V_{d}$ is rectified from the utility line. The anode of magnetron is grounded to the heat sink. The APS supplies a negative dc voltage to the cathode and the FPS heats the filament with a small ac voltage. To preheat the filament, switch $\mathrm{S} 1$ is turned on before switch S2.

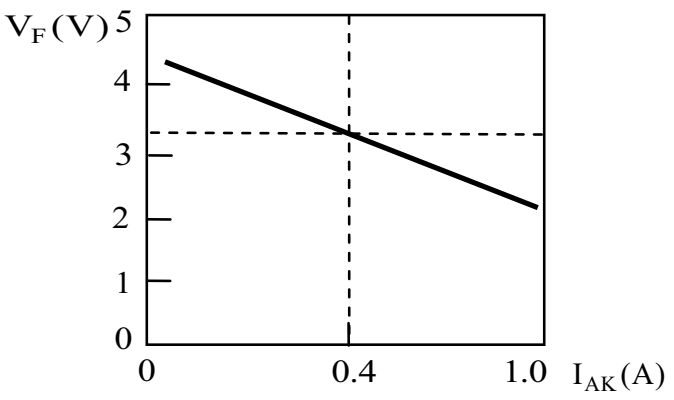

Fig. 1. The required filament voltage decreased with the average anode current.

Currently, there are many types of soft-switching circuits can be used to improve the circuit efficiency and 
reduce the volume and weight of power supplies. Due to simplicity and reliability, single-switch zero-voltageswitching (ZVS) circuits have been widely used in induction heating, cooking, LCD TV, EV chargers and other industrial applications [4-10].

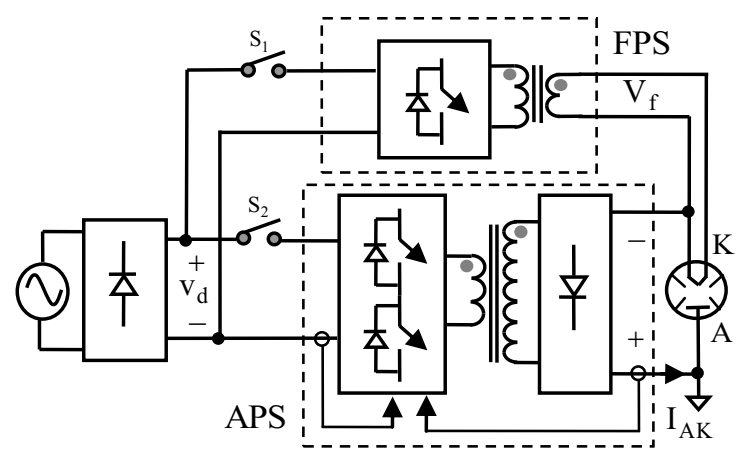

Fig. 2. The block diagram of an off-line magnetron driver.

\section{Circuit operations}

Fig.3 shows the circuit diagram of the FPS designed in this paper. It is a voltage-fed single-switch ZVS inverter. A step-down transformer is used to attain the required voltage conversion ratio and the secondary voltage drives the cathode filament.

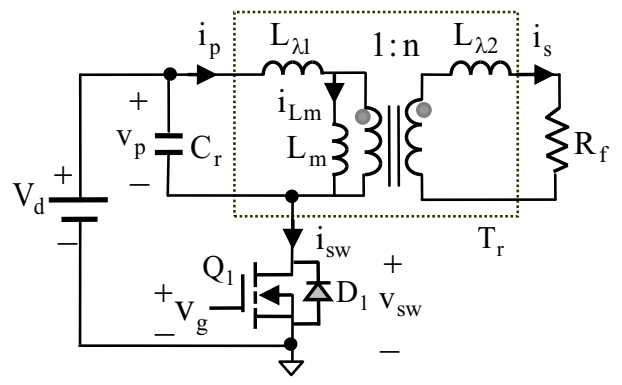

Fig. 3. The circuit diagram of single-switch ZVS inverter.

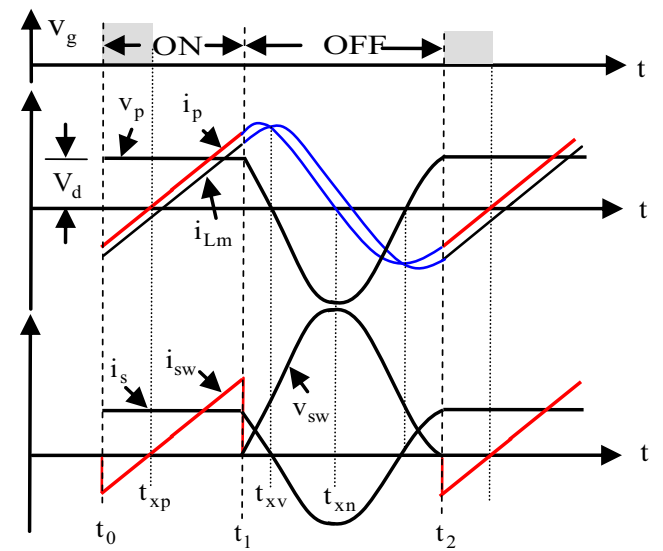

Fig. 4. The principal waveforms of single-switch ZVS inverter.
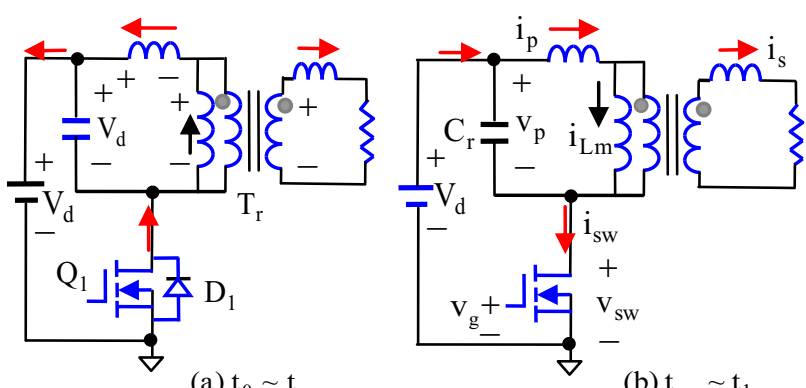

(a) $t_{0} \sim t_{x p}$

(b) $t_{x p} \sim t_{1}$
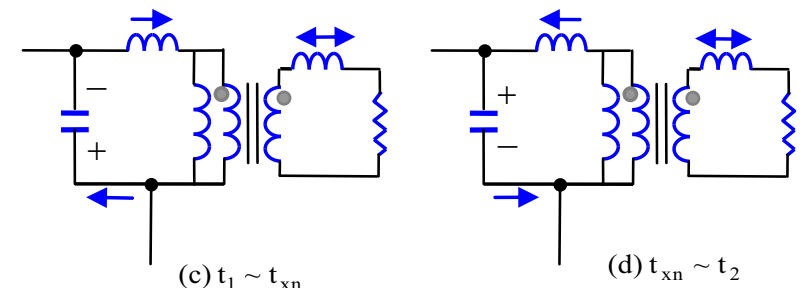

Fig. 5. The circuit operations of the single-switch ZVS inverter.

As switch $Q_{1}$ is turned off, transformer $T_{r}$ and capacitor $\mathrm{C}_{\mathrm{r}}$ comprise a parallel resonant tank. The primary leakage inductance and the transistor output capacitance are included in the resonant tank. By lowdamped resonance, the resonant energy makes the resonant voltage reach the dc voltage $V_{d}$. Thus, switch $\mathrm{Q}_{1}$ can be turned on at zero-voltage condition and hence switch loss is reduced. Fig.4 conceptually shows the current and voltage waveforms of the ZVS inverter. According to the primary current waveform, a switching cycle is divided into four stages. The detailed circuit operations are sketched in Fig.5.

At $\mathrm{ON}$ stage, $\mathrm{t}_{0}<\mathrm{t}<\mathrm{t}_{1}$, the primary voltage equals to $V_{d}$. The switch current $i_{s w}$ is negative at $t_{0}$. Since $\mathrm{D}_{1}$ is conducted, $\mathrm{Q}_{1}$ is turned on at zero voltage condition. After $t_{x p}$, switch current rises from zero. $A s Q_{1}$ is cut off at $t_{1}$, the OFF stage begins. At OFF stage, $t_{1}<t<t_{2}, T_{r}$ resonates with capacitor $C_{r}$, and the filament $R_{f}$ consumes the resonant energy. At $t_{x n}$, the sinusoidal resonant current crosses zero and the resonant voltage reaches maximum. By small damping ratio, the primary resonant voltage rises to $V_{d}$ at $t_{2}$. Then, $D_{1}$ naturally conducts and $\mathrm{Q}_{1}$ can be turned on at zero voltage condition.

\section{Circuit analyses}

Fig.6 shows a simplified resonant circuit, where $L_{p}$ is the primary inductance, $\mathrm{L}_{\mathrm{p}}=\mathrm{L}_{\mathrm{m}}+\mathrm{L}_{\lambda 1}, \mathrm{~L}_{\mathrm{m}}$ is the magnetizing inductance, $\mathrm{L}_{\mathrm{m}}=\mathrm{kL}_{\mathrm{p}}, \mathrm{k}$ is the transformer coupling factor, $\mathrm{k}=\mathrm{L}_{\mathrm{m}} /\left(\mathrm{L}_{\mathrm{m}}+\mathrm{L}_{\lambda 1}\right) . \mathrm{C}_{\mathrm{sw}}$ is the switch output capacitance and $\mathrm{C}_{\mathrm{p}}$ is the primary capacitance, $\mathrm{C}_{\mathrm{p}}=\mathrm{C}_{\mathrm{r}}+\mathrm{C}_{\mathrm{sw}}$. As the secondary leakage inductance is 
ignored, the primary resistance can be approximated as $\mathrm{R}_{\mathrm{p}} \approx \mathrm{R}_{\mathrm{f}} / \mathrm{n}^{2}$. For driving low resistance filament, the transformer turn ratio is much less than unity, $\mathrm{n}=\mathrm{N}_{\mathrm{s}} / \mathrm{N}_{\mathrm{p}}<<1$. The initial inductor current and initial capacitor voltage are $I_{0}$ and $V_{0}$ respectively.

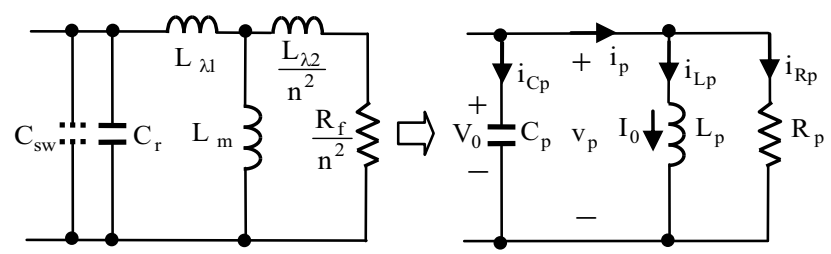

Fig. 6. The simplified equivalent circuit.

With coupling factor $\mathrm{k}$ and turn ratio $\mathrm{n}$, the secondary voltage of ON stage can be approximately expressed as

$$
\mathrm{v}_{\mathrm{s}}\left(\mathrm{t}-\mathrm{t}_{0}\right) \approx \mathrm{knv}_{\mathrm{p}}\left(\mathrm{t}-\mathrm{t}_{0}\right)=\mathrm{knV}_{\mathrm{d}} .
$$

The transformer secondary current is

$$
\mathrm{i}_{\mathrm{s}}\left(\mathrm{t}-\mathrm{t}_{0}\right) \approx \frac{\mathrm{knV}_{\mathrm{d}}}{\mathrm{R}_{\mathrm{f}}}+\left[\mathrm{i}_{\mathrm{s}}\left(\mathrm{t}_{0}\right)-\frac{\mathrm{knV}_{\mathrm{d}}}{\mathrm{R}_{\mathrm{f}}}\right] \exp \left[-\frac{\mathrm{R}_{\mathrm{f}}}{\mathrm{L}_{\lambda 2}}\left(\mathrm{t}-\mathrm{t}_{0}\right)\right]
$$

At OFF stage, the characteristic equation of resonant tank is

$$
\mathrm{s}^{2}+\frac{1}{\mathrm{R}_{\mathrm{p}} \mathrm{C}_{\mathrm{p}}} \mathrm{s}+\frac{1}{\mathrm{~L}_{\mathrm{p}} \mathrm{C}_{\mathrm{p}}}=\mathrm{s}^{2}+2 \alpha \mathrm{s}+\omega_{0}^{2}=0
$$

Here $\alpha$ is the damping factor, $\alpha=\frac{1}{2 R_{p} C_{p}}, \omega_{0}$ is the natural frequency, $\omega_{0}=\frac{1}{\sqrt{\mathrm{L}_{\mathrm{p}} \mathrm{C}_{\mathrm{p}}}}$. The damping ratio is $\xi=\frac{\alpha}{\omega_{0}}$. With the loaded quality factor $Q_{L},(3)$ can be rewritten as

$$
\mathrm{s}^{2}+2 \alpha \mathrm{s}+\omega_{0}^{2}=\mathrm{s}^{2}+\frac{\omega_{0}}{\mathrm{Q}_{\mathrm{L}}} \mathrm{s}+\omega_{0}^{2}=0
$$

$\mathrm{Q}_{\mathrm{L}}=\frac{\omega_{0}}{2 \alpha}=\frac{1}{2 \xi}=\frac{\mathrm{R}_{\mathrm{p}}}{\mathrm{Z}_{0}}, \mathrm{Z}_{0}=\omega_{0} \mathrm{~L}_{\mathrm{p}}=\frac{1}{\omega_{0} \mathrm{C}_{\mathrm{p}}}=\sqrt{\frac{\mathrm{L}_{\mathrm{p}}}{\mathrm{C}_{\mathrm{p}}}}$.

For under-damped case, $\xi<1$ or $\mathrm{Q}_{\mathrm{L}}>0.5$, the characteristic equation has two conjugate complex roots,

$$
s_{1,2}=-\alpha \pm j \omega_{d}, \omega_{d}=\sqrt{\omega_{0}^{2}-\alpha^{2}} .
$$

The natural voltage response of the primary is

$$
\mathrm{v}_{\mathrm{p}}(\tau)=\mathrm{e}^{-\alpha \tau}\left[\mathrm{B}_{1} \cos \left(\omega_{\mathrm{d}} \tau\right)+\mathrm{B}_{2} \sin \left(\omega_{\mathrm{d}} \tau\right)\right], \tau=\mathrm{t}-\mathrm{t}_{1}
$$

With initial conditions,

$$
\mathrm{v}_{\mathrm{p}}(0)=\mathrm{V}_{0}, \frac{\mathrm{dv}_{\mathrm{p}}(0)}{\mathrm{dt}}=\frac{\mathrm{V}_{0}}{\mathrm{R}_{\mathrm{p}} \mathrm{C}_{\mathrm{p}}}+\frac{\mathrm{I}_{0}}{\mathrm{C}_{\mathrm{p}}},
$$

the constants $\mathrm{B}_{1}$ and $\mathrm{B}_{2}$ are determined.

$$
B_{1}=V_{0}, B_{2}=V_{0} \frac{\alpha}{\omega_{d}}-\left(I_{0}+\frac{V_{0}}{R}\right) \frac{1}{\omega_{d} C_{p}}
$$

With the voltage response, the resistive current is

$$
\mathrm{i}_{\mathrm{Rp}}(\tau)=\mathrm{v}_{\mathrm{p}}(\tau) / \mathrm{R}_{\mathrm{p}}
$$

The inductive current obtained by the KCL is

$$
i_{L p}(\tau)=-i_{R p}(\tau)-i_{C p}(\tau), i_{C p}(\tau)=C_{p} \frac{d v_{p}(\tau)}{d t}
$$

For un-damped case, $\alpha=0, \mathrm{~B}_{1}=\mathrm{V}_{0}, \mathrm{~B}_{2}=\mathrm{I}_{0} \mathrm{Z}_{0}$, the primary voltage and current are respectively

$$
\begin{aligned}
& \mathrm{v}_{\mathrm{p}}(\tau)=\mathrm{V}_{0} \cos \left(\omega_{0} \tau\right)-\mathrm{I}_{0} \mathrm{Z}_{0} \sin \left(\omega_{0} \tau\right) \\
& \mathrm{i}_{\mathrm{p}}(\tau)=\mathrm{I}_{0} \cos \left(\omega_{0} \tau\right)+\frac{\mathrm{V}_{0}}{\mathrm{Z}_{0}} \sin \left(\omega_{0} \tau\right)
\end{aligned}
$$

The primary voltage equation (10) can be written as

$$
\mathrm{v}_{\mathrm{p}}(\tau)=-\mathrm{V}_{\mathrm{pk}} \sin \left(\omega_{0} \tau-\phi\right)
$$

$\mathrm{V}_{\mathrm{pk}}=\mathrm{V}_{0} \sqrt{1+\gamma^{2}}, \gamma=\frac{\mathrm{I}_{0} \mathrm{Z}_{0}}{\mathrm{~V}_{0}}, \phi=\sin ^{-1}\left(\frac{1}{\sqrt{1+\gamma^{2}}}\right)$.

As shown in Fig.4, the parallel resonance begins at $t_{1}$ and ends at $t_{2}$. The resonant voltage crosses zero at $t_{x v}$ and the phase angle between $t_{x v}$ and $t_{1}$ is $\phi$. The total angle of the OFF stage is $\pi+2 \phi$. As the angle of ON stage is expressed as $\delta \pi, 0<\delta<1$. The relation between $\delta$ and $\gamma$ can be found by the volt-second balance.

$$
\mathrm{V}_{\mathrm{d}} \delta \pi+2 \int_{0}^{\phi} \mathrm{v}_{\mathrm{p}}(\theta-\phi) \mathrm{d} \theta=\int_{\phi}^{\pi+\phi} \mathrm{v}_{\mathrm{p}}(\theta-\phi) \mathrm{d} \theta-\pi \mathrm{V}_{\mathrm{d}}
$$

$\theta=\omega_{0} \mathrm{t}$. For undamped case, $\alpha=0$,

$$
\delta=\gamma \frac{2}{\pi}-1
$$

The voltage stress applied on the switch $Q_{1}$ is

$$
\mathrm{V}_{\mathrm{sw}}=\mathrm{V}_{\mathrm{d}}+\mathrm{V}_{\mathrm{pk}}=\mathrm{V}_{\mathrm{d}}\left(1+\sqrt{1+\gamma^{2}}\right)
$$

In case that $\delta=0.3, \gamma=2.04, \mathrm{~V}_{\mathrm{sw}}=3.27 \mathrm{~V}_{\mathrm{d}}$.

In order to reduce the switch voltage stress, the interval of the ON stage should be decreased and hence a smaller inductance and a larger capacitance are adopted at the desired natural angular frequency. 
To easily obtain the ZVS condition, the damping ratio of the RLC tank should be smaller than 0.1 . Namely, the loaded quality factor should be greater than 5. In case of $\xi \leq 0.1$, the primary minimum resistance is $\mathrm{R}_{\mathrm{p}} \geq 5 \mathrm{Z}_{0}$. With the minimum resistance, the condition of the characteristic impedance can be expressed as

$$
\sqrt{\frac{\mathrm{L}_{\mathrm{p}}}{\mathrm{C}_{\mathrm{p}}}} \leq \frac{\mathrm{R}_{\mathrm{f}, \min }}{5 \mathrm{n}^{2}}
$$

As the exponential term of (2) is ignored, the energy dissipated at the ON stage can be expressed as

$$
\mathrm{W}_{\mathrm{ON}}=\int_{\mathrm{t}_{0}}^{\mathrm{t}_{1}} \mathrm{i}_{\mathrm{s}}^{2}\left(\mathrm{t}-\mathrm{t}_{0}\right) \mathrm{R}_{\mathrm{f}} \mathrm{dt}, \mathrm{i}_{\mathrm{s}}\left(\mathrm{t}-\mathrm{t}_{0}\right) \approx \frac{\mathrm{knV}_{\mathrm{d}}}{\mathrm{R}_{\mathrm{f}}}
$$

At OFF stage, the dissipated energy can be expressed as

$$
\mathrm{W}_{\mathrm{OFF}}=\int_{\mathrm{t}_{1}}^{\mathrm{t}_{2}} \mathrm{i}_{\mathrm{s}}^{2}(\tau) \mathrm{R}_{\mathrm{f}} \mathrm{dt}, \mathrm{i}_{\mathrm{s}}(\tau) \approx \frac{\mathrm{knv}_{\mathrm{p}}(\tau)}{\mathrm{R}_{\mathrm{f}}}, \tau=\mathrm{t}-\mathrm{t}_{1}
$$

\section{Simulation and experiment}

An off-line single-switch ZVS inverter circuit is designed for a $33 \mathrm{~W} / 3 \mathrm{~V}$ filament. The widely used 8-pin control chip L6561 is used to control the switch conduction time and detect the zero point of switch voltage. The switching frequency is about $20 \mathrm{kHz}$ at rated power and input voltage. To easily obtain the ZVS condition, the loaded quality factor of the RLC parallel resonant tank is set larger than 5. The designed circuit parameters are listed as follows.

$$
\begin{aligned}
& \mathrm{P}_{\mathrm{avg}}=33 \mathrm{~W} \quad . \quad \mathrm{R}_{\mathrm{f}, \min }=0.16 \Omega \quad, \quad \mathrm{R}_{\mathrm{f}}=0.32 \Omega, \\
& \mathrm{V}_{\mathrm{d}}=300 \mathrm{~V}, \mathrm{n}=0.02, \mathrm{k}=0.92, \quad \mathrm{~L}_{\mathrm{p}}=480 \mathrm{uH}, \\
& \mathrm{C}_{\mathrm{p}}=0.1 \mathrm{uF}, \mathrm{Z}_{0}=69 \Omega, \mathrm{f}_{\mathrm{sw}} \geq 20 \mathrm{kHz} .
\end{aligned}
$$

Fig.7 displays the natural responses of the primary voltage with initial voltage $300 \mathrm{~V}$ and initial current $6 \mathrm{~A}$. The four traces respectively correspond to the $0.1,0.16$, 0.32 and $100 \mathrm{Ohms}$ filaments. It illustrates that the RLC parallel circuit with above initial conditions can obtain the ZVS operation while the filament is greater than 0.1 $\mathrm{Ohm}$, and the corresponding switch voltage stress at $100 \mathrm{Ohms}$ load is about $800 \mathrm{~V}$.

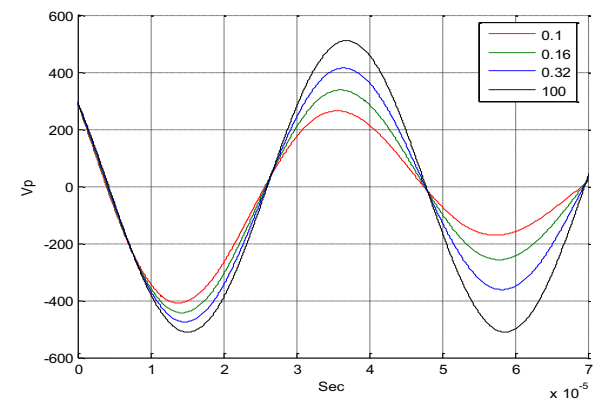

Fig. 7. The simulation of characteristic equation at four different loads.
Fig.8, Fig.9, and Fig.10 respectively show the waveforms simulated at $100 \Omega, 0.32 \Omega$, and $0.16 \Omega$ loads. It can be found that the reflected current increases with the decrease of the filament resistance. As shown in Fig.8, the transformer magnetizing current is equal to the primary current, and the negative switch current that flows through the anti-parallel diode is greater than that of Fig.9 and Fig.10. The switch voltage stress is about $800 \mathrm{~V}$. The simulated waveforms demonstrate the circuit analyses. The switch current is a part of the primary current, and the difference between the primary and the magnetizing currents is the reflected load current. The transistor switch obtains the ZVS operation and the sinusoidal resonant waveforms can be observed at the OFF stage. Fig.11 and Fig.12 display the practical waveforms of a scale-down inverter respectively measured at light-load and heavy-load conditions. The ac output voltage of the inverter is rectified and filtered to a dc signal and then fed back to the control chip L6561 to control the conduction time of switch. The output power of the ZVS inverter is dominated by the switch conduction time. And, the switch off time is determined by the resonant parameters. The measured waveforms coincide with the simulated waveforms. The waveforms shown in Fig.13 depict the relation between the filament current and the anode to cathode voltage. At start-up stage, the inverter heats the filament, and the preheating time lasts about 3 seconds. The anode to cathode voltage reaches about $7 \mathrm{kV}$. In order to protect the magnetron from high voltage stress, the anode power supply should be turned on after the pre-heating process.

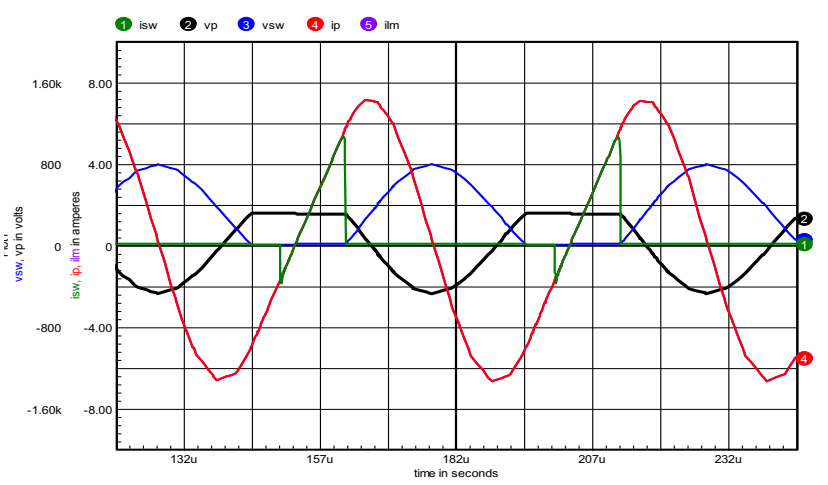

Fig. 8. The waveforms simulated with $100 \mathrm{Ohms}$ load.

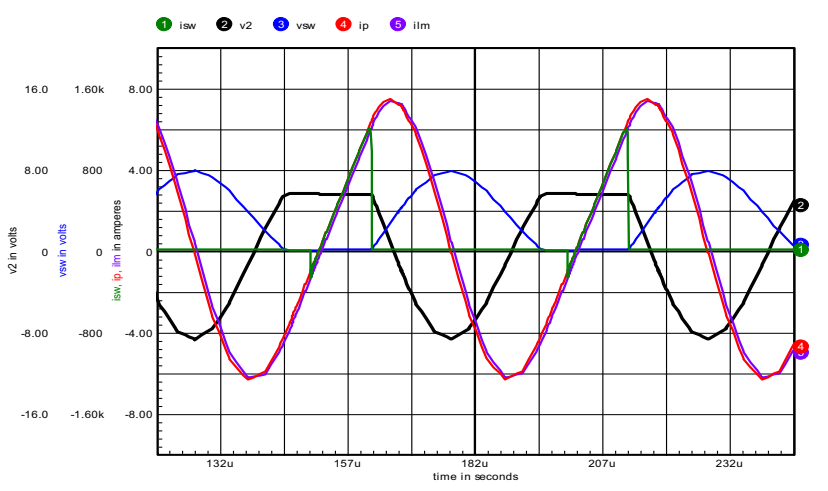

Fig. 9. The waveforms simulated with 0.32 Ohms load. 


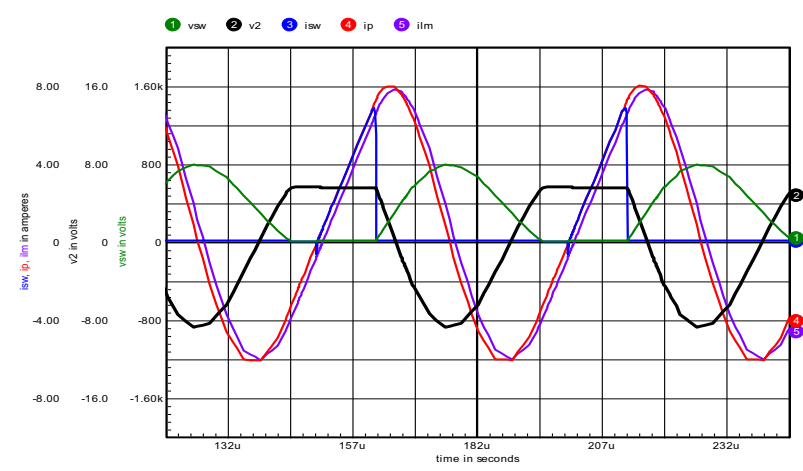

Fig. 10. The waveforms simulated with $0.16 \mathrm{Ohms}$ load.

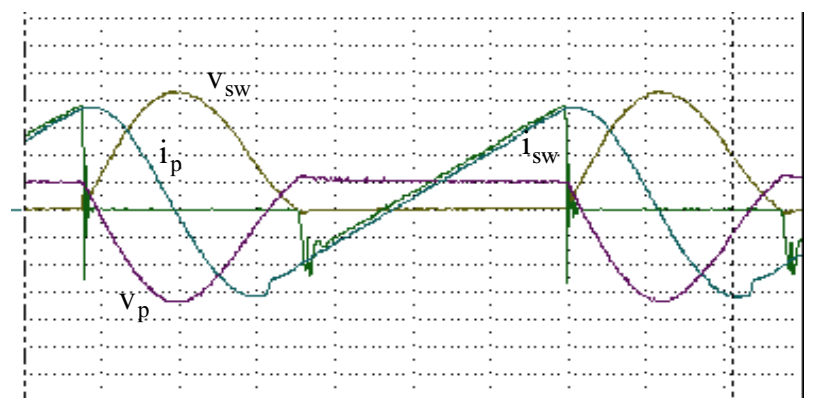

Fig. 11. The steady-state waveforms at light load conditions.

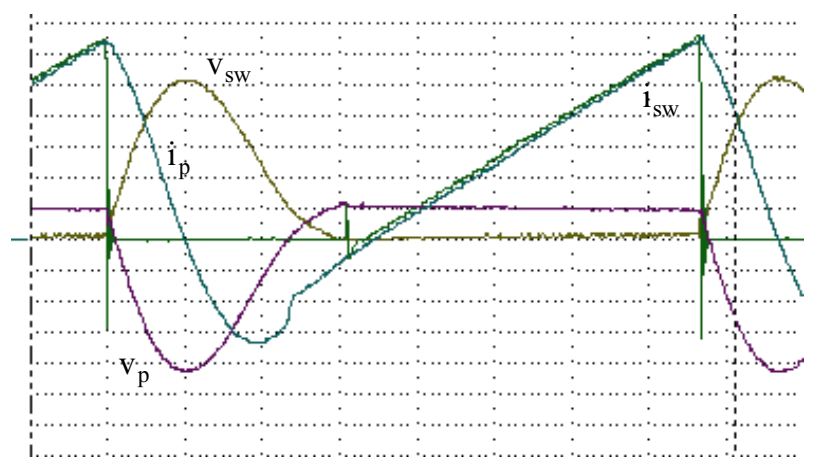

Fig. 12 The steady-state waveforms at heavy load conditions.

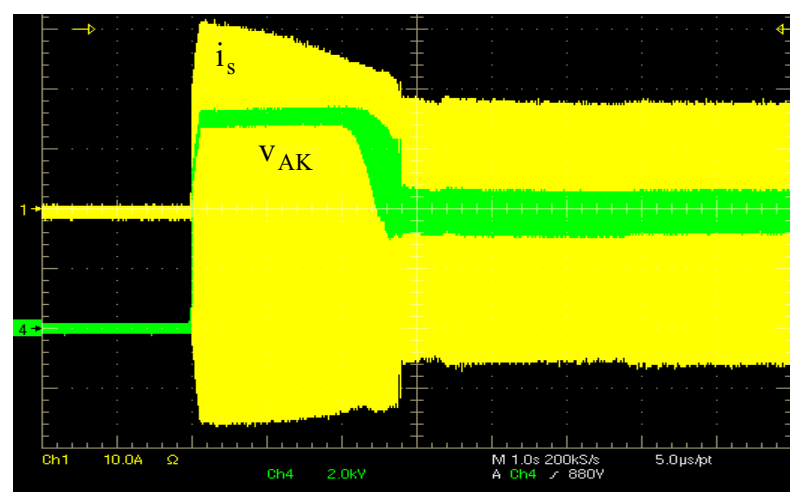

Fig. 13 The waveforms of filament current (10A/Div) and anode to cathode voltage ( $2 \mathrm{kV} / \mathrm{Div})$ at start-up stage, Time:1s/Div.

\section{Conclusions}

Before applying dc high voltage to a cooker magnetron, the cathode filament is preheated to reach the thermionic emission temperature. As the magnetron starts working, the filament power is regulated according to average anode current. This paper designs an off-line singleswitch zero-voltage-switching inverter as the filament power supply. As the transistor switch of the inverter is turned on, the input voltage drives the cathode filament via a step-down isolation transformer. As the transistor switch is turned off, the transformer resonant voltage drives the filament. The output power is dominated by the switch conduction time. The resonant parameters determine the switch off time.

This work is supported by the MOST of Taiwan; the contract number is MOST 107-2637-E-131-003.

\section{References}

1. G.E. Georghiou, R. Meredith, A.C. Metaxas and D. Gurwicz, "Switch Mode Power Supply for Microwave Heating Based on the Boucherot Effect," Journal of Microwave Power and Electromagnetic Energy, vol.34, no.4, pp.206-215, (1999).

2. Luiz P. P Junior, Marcos E. T, Juliano S. B. and Leandro M., "Modeling and control of a high-frequency magnetron power supply for microwave heating applications," IEEE Brazilian Power Electronics Conference COBEP/SPEC, (2015), pp.1-6.

3. S-R Jang, H-J Ryoo, S-H Ahn, J-S Kim and G-H Rim, "Development and Optimization of High-Voltage Power Supply System for Industrial Magnetron," IEEE Trans. I.E., vol.59, no. 3, pp.1453-1461, March (2012).

4. S-H Ryu, J-H Ahn, K-S Cho and B-K Lee, "Single-Switch ZVZCS Quasi-Resonant CLL Isolated DC-DC converter for 32" LCD TV," J Electr Eng Technol., (2015); 10(4):1646-1654.

5. J-M Kwon, W-Y Choi, and B-H Kwon, "Single-switch QuasiResonant Converter," IEEE Trans., Industrial Electronics, vol.56, no. 4, April (2009).

6. M. Saoudi, D. Puyal, C. Bernal, D. Anton and A. Mediano, "Induction cooking systems with single switch inverter using new driving techniques," (2010) IEEE international Symposium on Industrial Electronics, ISIE, pp.878-883.

7. Shweta Hegde and Afshin Izadian "Control of single switch inverters," Power and Energy Conference at Illinois (PECI), (2014). pp. $1-6$.

8. C. Bernal, J. Avellaned and J. Milla, "Single switch quasi-resonant inverter on Silicon Carbide with regenerative snubber for induction heating appliances," (2014) 16th European Conference on Power Electronics and Applications, pp.1-5.

9. Yuya Kitano; Hideki Omori; Noriyuki Kimura; Toshimitsu morizane; Kunio Nakagawa; Mutsuo Nakaoka "A new wireless EV charger using single switch ZVS resonant inverter with optimized power transfer and low-cost PFC," (2015) International Conference on Electrical Drives and Power Electronics (EDPE), pp.515-521.

10. Lukasz Roslaniec, Alexander S. Jurkov, Anas Al Bastami, and David J. Perreault "Design of Single-Switch Inverters for Variable Resistance/Load Modulation Operation," IEEE Trans. Power Electronics, vol.30, no. 6, pp.3200-3214, (2015). 